\title{
Introducing Views on Cartographic Education
}

\section{INTRODUCTION}

The mapmaking process has evolved from hand-drawn linework on vellum to an interwoven, digitally and technologically rich fabric. This evolution has permeated the entirety of the cartographic process, including data collection, which software and applications are used to make maps, and how maps are disseminated. Cartographic instructors and, in fact, anyone who has participated in mapmaking for any length of time, have witnessed continuous technological advances that have enabled, for example, web, mobile, and cloud mapping. These are truly interesting times to be a cartographer.

In spite of the attractiveness of where cartography presently is situated, one should remain vigilant as to the promise of where it may venture. For the professional, keeping pace with the constantly changing technologies can be quite challenging. While often promising, new technologies do not necessarily retain their original luster as newer versions quickly supersede previous ones. More specifically, cartography instructors often must pick and choose which technologies are most appropriate to integrate into their curriculum. Although technological evolution has been a factor throughout the history of mapmaking, the present pace of technological change is particularly rapid, and shows no signs of slowing. It is this changing cartographic landscape, and questions over how to deliver a current and relevant curriculum, that form the scope of this special issue of Cartographic Perspectives. This special issue on cartographic education is also the platform for launching a new section titled Views on Cartographic Education.

\section{RATIONALE FOR NEW SECTION}

When developing content for a cartography course, many instructors probably tap into material they experienced during their own college classes. Others modify those previous lessons by integrating new content from various outside resources focused on teaching specific ideas. Still others create fresh approaches to instructing students how to make maps. Views on Cartographic Education is designed to provide a forum for cartography instructors to share ideas on what worked in the classroom and what didn't. This new section will allow the sharing of teaching experiences (both good and bad aspects) with other instructors, promote the development of a standard content for cartography courses, and act as a resource for current professional cartographers seeking to learn the new skills and knowledge needed for a rapidly changing career field.

\section{TARGET READERSHIP}

This new section is not intended to be an outlet for academics pursuing original peer-reviewed research or controlled experimentation dealing with cartographic education (although CP's Editor would welcome these kinds of submissions!). Rather, this section is intended to be a forum where pedagogical experiences in cartographic instruction in the classroom or the lab environment, and beyond, are shared. Of particular interest to readers are novel approaches instructors take to teaching cartography. In addition to the more traditional academic classroom environment, this section will appeal to a larger non-academic group. For instance, cartography lab employees can seek out information from this section to help with their workflow efficiency, secondary school teachers can see an activity that could be incorporated into their classroom as an exercise on map design, programmers can find new code samples that they can include in software, and casual mappers can learn how to use newly developed open source mapping software. In other words, topics found in this section are not intended to only appeal to those teaching in a traditional academic classroom environment, but to the larger cartographic community. 


\section{POSSIBLE CONTENT IDEAS}

Below are a few possible ideas on content for this new section:

- Share lab exercises where clear learning goals are stated and outcomes can be assessed

- Debate as to what constitutes the range of appropriate content in cartography courses

- What pedagogical approaches have been successful when teaching content that is challenging?

- Discuss successes and failures resulting from an experiential teaching/learning process

- Introduce novel ways of teaching cartographic content

- Discuss the use of multimedia such as YouTube videos, to teach cartographic topics

- Report on new technology and how this technology could be integrated into the classroom

- Details of interesting or challenging classroom experiences

- Results of or ideas on engaging students with projects outside the lab environment (e.g., community outreach)

\section{THIS SECTION NEEDS YOU!}

Content for this new section is welcomed from around the cartographic community: instructors at institutions of higher education, mapping software developers, professionals in private industry, freelancers, government employees, and more. All are encouraged to share their teaching experiences and/or their practical "how-to" knowledge. The pool of potential contributors is vast, and you are encouraged to be a part of it!

\section{THE SUBMISSION AND REVIEW PROCESS}

The submission process is handled through CP's journal management system. To submit your article for consideration, please visit cartographicperspectives.org for specific guidance on the submission process. Articles submitted for publication consideration to this new section will undergo a modified review process. All articles will be vetted by the Section Editor and two reviewers, who will comment on the article's clarity, currency, and degree of interest to $C P$ 's readership. The publication decision will mirror that which is used for articles appearing in $C P$ 's peer-reviewed sections.

\section{SUGGESTIONS TO AUTHORS}

In writing an article for this new section the following three points should be kept in mind. First, authors should explain the rationale and motivation for the article. In other words, there should be some discussion as to why this article was penned (e.g., experimentation with a novel teaching approach) and why the reader would be interested in this information. Second, the author should reflect on the outcomes of the experience. These reflections should include results that were deemed both good and bad. Third, illustrations, screen captures, and images are especially encouraged to be submitted as part of the article. Evidence of instructional outcomes through finished map examples is particularly encouraged.

Articles submitted to this section should be between 1,000 and 2,500 words. Depending on content, longer or shorter submissions will also be considered.

Fritz Kessler,

Section Editor 